\title{
Full Scope Modeling and Analysis on the Secondary Circuit of Chinese Large-Capacity Advanced PWR Based on RELAP5 Code
}

\author{
Dao-gang Lu, ${ }^{1,2}$ Fan Zhang, ${ }^{1,2}$ Dan-ting Sui, ${ }^{1,2}$ Xue-zhang $\mathrm{Xi}^{3}$ and Lei-bo $\mathrm{Yu}^{3}$ \\ ${ }^{1}$ School of Nuclear Science and Engineering, North China Electric Power University, Beijing 102206, China \\ ${ }^{2}$ Beijing Key Laboratory of Passive Nuclear Safety Technology, North China Electric Power University, Beijing 102206, China \\ ${ }^{3}$ State Nuclear Electric Power Planning Design \& Research Institute, Beijing 100095, China \\ Correspondence should be addressed to Fan Zhang; hdhxyzf@126.com
}

Received 2 March 2015; Revised 3 June 2015; Accepted 4 June 2015

Academic Editor: Iztok Tiselj

Copyright (C) 2015 Dao-gang Lu et al. This is an open access article distributed under the Creative Commons Attribution License, which permits unrestricted use, distribution, and reproduction in any medium, provided the original work is properly cited.

\begin{abstract}
Chinese large-capacity advanced PWR under construction in China is a new and indispensable reactor type in the developing process of NPP fields. At the same time of NPP construction, accident sequences prediction and operators training are in progress. Since there are some possible events such as feedwater pumps trip in secondary circuit may lead to severe accident in NPP, training simulators and engineering simulators of CI are necessary. And, with an increasing proportion of nuclear power in China, NPP will participate in regulating peak load in power network, which requires accuracy calculation and control of secondary circuit. In order to achieve real-time and full scope simulation in the power change transient and accident scenarios, RELAP5/MOD 3.4 code has been adopted to model the secondary circuit for its advantage of high calculation accuracy. This paper describes the model of steady state and turbine load transient from $100 \%$ to $40 \%$ of secondary circuit using RELAP5 and provides a reasonable equivalent method to solve the calculation divergence problem caused by dramatic two-phase condition change while guaranteeing the heat transfer efficiency. The validation of the parameters shows that all the errors between the calculation values and design values are reasonable and acceptable.
\end{abstract}

\section{Introduction}

Speeding up the development of nuclear power is an inevitable way to solve the energy crisis and environmental problems caused by pollution of fossil energy. Since the largecapacity advanced PWR is a new and indispensable reactor type in the developing process of nuclear power plant fields, the enthusiasm of research on it increases gradually. Chinese large-scale advanced PWR which is under construction in China is the research subject in this paper. On the one hand, with an increasing proportion of nuclear power in the electric power in China, nuclear power plant (NPP) will participate in regulating peak load in power network by load and frequency adjustment; on the other hand, there are some possible events such as steam turbine failure and feedwater pumps or other pumps trip in secondary circuit which may lead to severe accident in NPP. Taking these two requirements into account, training simulators and engineering simulators of conventional island (CI) are necessary.
The proportion of transient analysis codes for conventional island of nuclear power plant system is small. SASSYS developed by Argonne National Laboratory is a general purpose one-dimensional thermal-hydraulic liquid-metal reactor (LMR) systems analysis code [1]. It is validated using the data of Experimental Breeder Reactor number 2 (EBR-II). SASSYS has some typical models for transient analysis, such as core thermal hydraulic model and heat transfer between fuel component models. The adding of Balance-of-Plant model to SASSYS makes it capable of achieving transient simulation for thermal hydraulic system in conventional island. Some accident scenarios have been studied using SASSYS such as closure of the turbine admission valve. Another code called NATDEMO developed by Argonne National Laboratory is special for EBR-II, including primary, feedwater, and steam systems [2]. Another code named DSNP provides a full scope simulation of power plant based on component or system model in libraries, which are continually updated with new, improved, and verified modules [3]. Verification of 


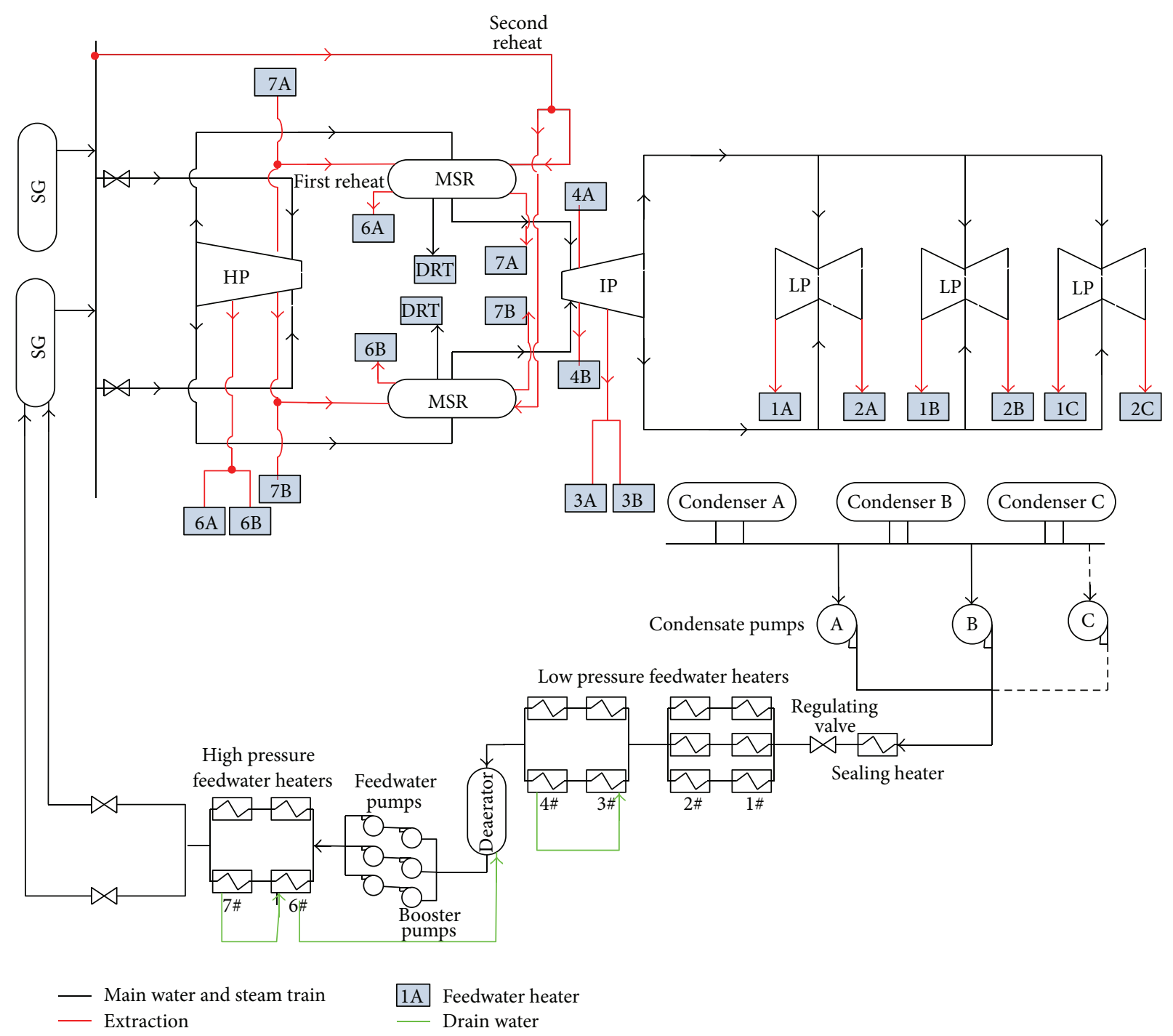

FIGURE 1: Flow sheet of feedwater and steam system of Chinese large-scale advanced PWR.

DSNP has been done by comparing the simulation programs calculation with EBR-II experiment data. The modules are used to simulate the dynamic response of reactor systems' transient conditions and BOP system perturbations.

Sharma et al. simulate BOP system of Prototype Fast Breeder Reactor (PFBR) based on RELAP5/MOD 3.4 code, and some of the important events possible in the steam water system have been analyzed using this code to verify the effectiveness of the procedure adopted, such as one CEP trip and standby not starting and one condenser cooling water pump (CCWP) trip [4]. Yang et al. developed a dual RELAP5-3Dbased engineering simulator for Lungmen advanced boiling water reactor (ABWR), which has two separate RELAP5$3 \mathrm{D}$ modules for reactor system and BOP system individually synchronized on a platform [5].

Since the accuracy, authenticity, and reliability of each part's model in system related to the effect of the whole plant simulation directly, RELAP5/MOD 3.4 code is used as the model tool in this study [6]. This paper describes the model of steady state and turbine load transient from $100 \%$ to $40 \%$ of CI. This model provides an easy interface with nuclear island system and a basic simulation for future accident analysis.

\section{Secondary Circuit Model Description}

Chinese large-scale advanced PWR is a two-circuit reactor [7]. As shown in Figure 1, thermal hydraulic system in conventional island consists of steam generator (SG) secondary side, high pressure turbine (HPT), two moisture separator reheaters (MSRs), intermediate pressure turbine (IPT), three low pressure turbines (LPTs), three condensers, three condensate extraction pumps (CEP), ten low pressure heaters in four stages (three number 1 low pressure heaters (LPH1), three LPH2, two LPH3, and two LPH4), deaerator, three feedwater pumps (FP) with dedicated booster pump (BP), four high pressure heaters in two stages (two number 6 high pressure heaters (HPH6) and two HPH7), and corresponding valves and pipes. 


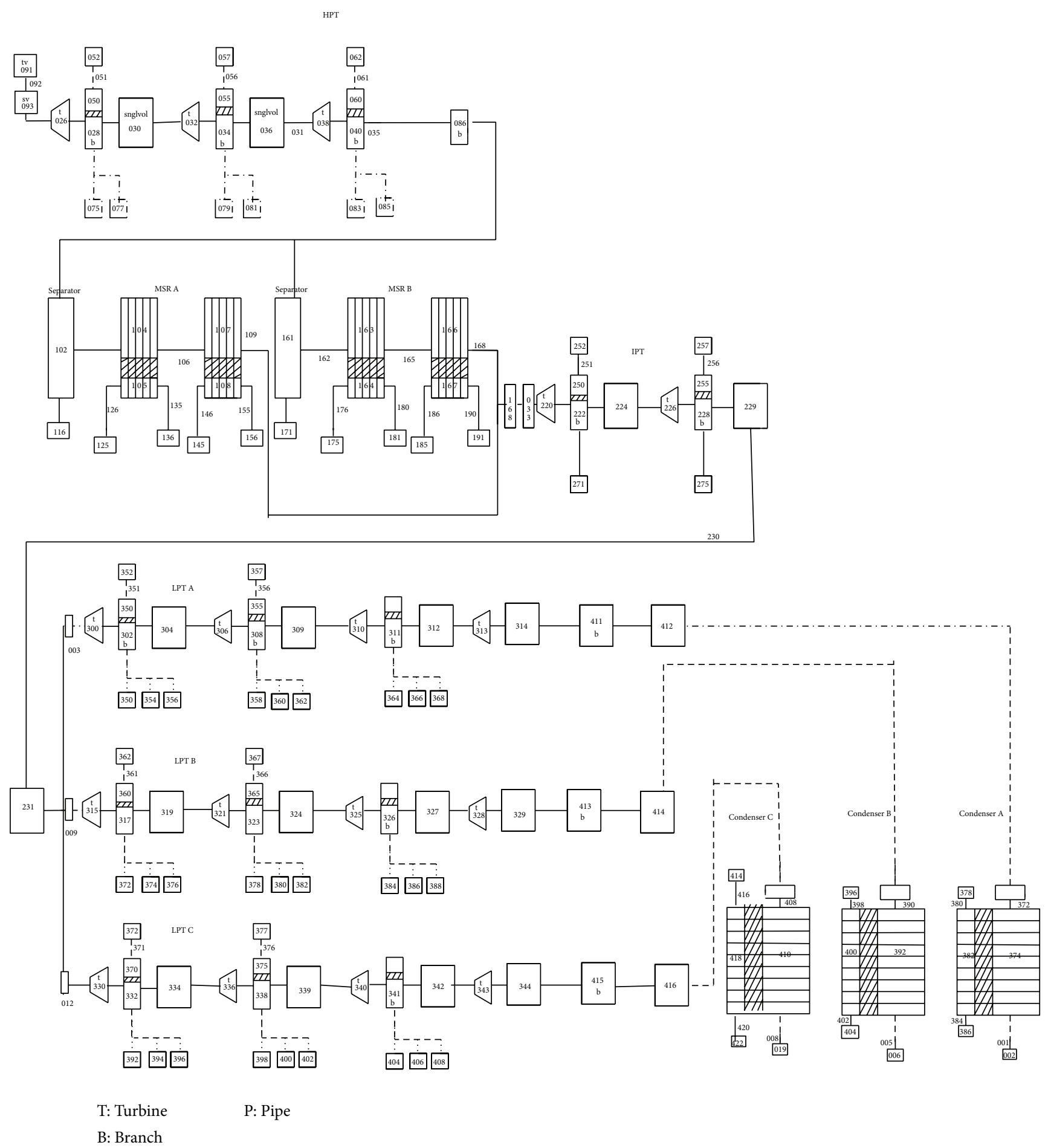

FIgURE 2: Nodal map of thermal-hydraulic system in conventional island (part I).

The RELAP5 model of secondary circuit of Chinese largescale advanced PWR has been built based on the practical system layout of NPP design shown in Figure 1. Figures 2-3 show the nodal map of thermal-hydraulic system in CI consisting of turbines, MSRs, condenser, condensate water pumps, $\mathrm{LPH}$, deaerator, feedwater pumps, booster pumps, HPH, and corresponding valves and pipes. In traditional simulation of CI, parallel running equipment is simplified as one with equivalent function. Different from it, the amount of equipment is coincided with actual layout of NPP in this model, which is convenient for simulating disconnection operation situation of certain equipment.

The turbine is the equipment where the internal energy of high temperature and pressure steam transforms into 


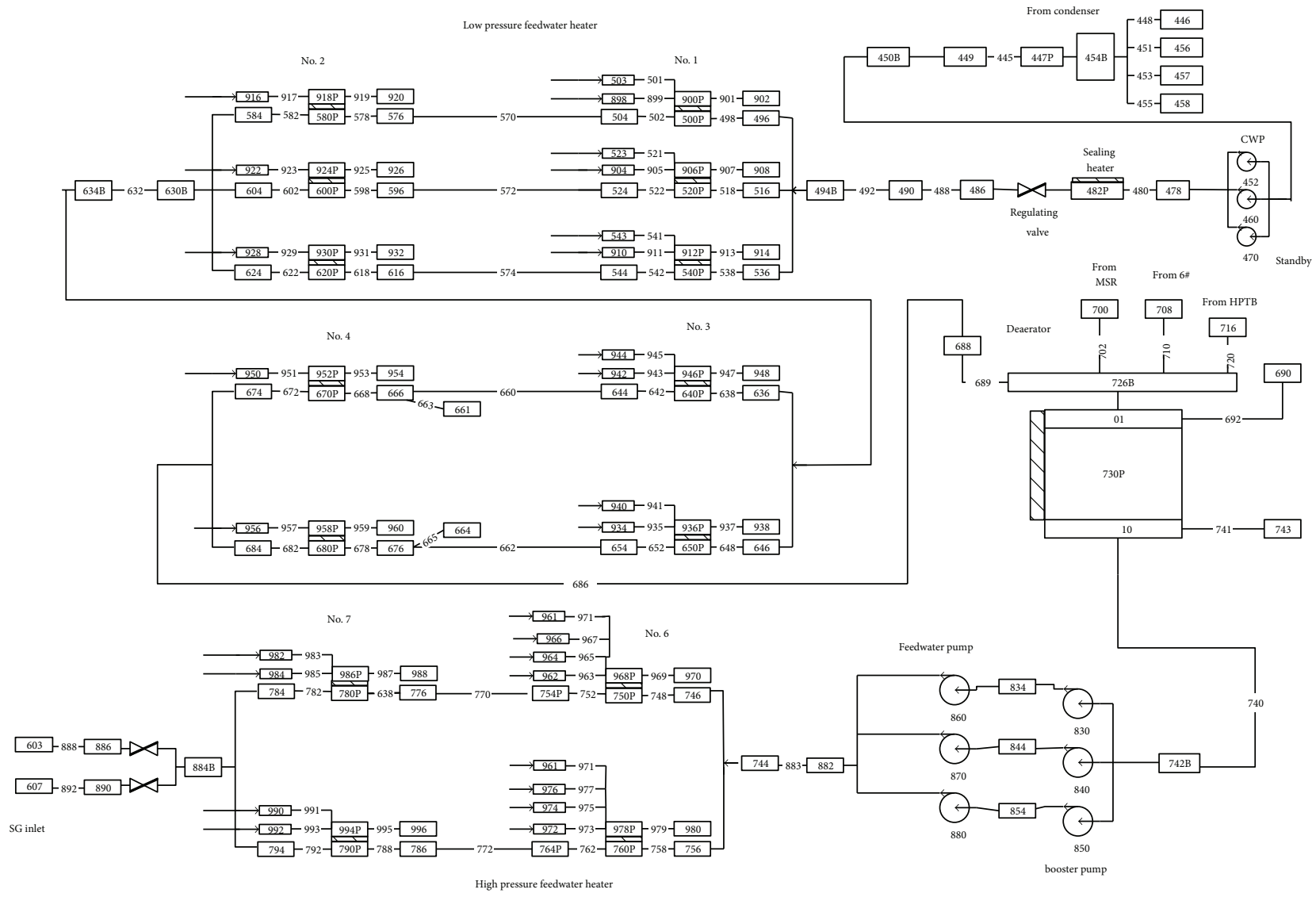

FIgURe 3: Nodal map of thermal-hydraulic system in conventional island (part II).

mechanical energy [8]. In RELAP5, the modified energy, momentum, and continuity equations have been used to calculate the stages of turbine. An effective factor should be set based on the simple consideration of momentum and energy to represent the ideal inner energy conversion process. In order to simulate the steam extraction in turbine here, the several stages are modeled by typical nuzzle-shape area instead of lumped-parameter model. The number of stages corresponds with the extraction train. A reasonable simplification is used in the model of extraction trains from turbine to heaters and deaerator; that is, instead of real connection with heater shell side, time dependent junction and time dependent volume are used to simulate the boundary of extraction. As shown in Figure 2, there are one HPT, one IPT, and three LPTs modeled precisely. HPT is modeled by three stages $(026,032$, and 038), IPT is modeled by two stages ( 220 and 226), and each LPT is modeled by four stages: 300,306 , 310 , and 313 for LPT A, 315, 321, 325, and 328 for LPT B, 330, 336, 340, and 343 for LPT C.

To prevent corrosion, MSRs pull moisture from the exhaust of turbines and reheat [9]. According to the operating principle of the model of each MSR which consists of three parts, two multiple steam separators are modeled using separator component, namely, 102 and 161; the first level reheaters are modeled by two pipes with a heat structure, whose shell sides are extraction steam boundaries, and second level reheaters' shell sides are live steam boundaries.

As shown in Figure 3, there are three condensate pumps in total, two of which are running normally while the third one is standby. When one of the running pumps trips, the standby pump comes into working. Condensate pumps are modeled by pump components, namely, 452, 460, and 470 (standby). There are three feedwater pumps $(830,840$, and 850 , resp.) and three booster pumps $(860,870$, and 880 , resp.). For simulating these nine pumps exactly, not only are geometrical parameters and operation-related parameters set, but also characteristic curves (head and torque curves) of each pump are modeled by homologous curve data. There are eight operation octants for each pump, all data are set to completely describe the single-phase pump operation, and data of two normal regimes are given particular concern.

Feedwater heaters are used to preheat water delivered to steam generators. Preheating the feedwater reduces the irreversibility involved in steam generation and therefore improves the thermodynamic efficiency of the system [10]. There are six levels of feedwater heaters in Chinese largecapacity advanced PWR. The temperature of feedwater arises when it flows through every level of heaters and reaches to the saturation temperature eventually. All of the heaters are modeled by two heat transfer pipes with a heat structure 
TABLE 1: Validation of steady-state parameters.

\begin{tabular}{lccc}
\hline Parameter & Calculation value & Nominal value & Error \\
\hline Turbine inlet pressure & $5.95 \mathrm{MPa}$ & $5.95 \mathrm{MPa}$ & 0.0 \\
Deaerator pressure & $1.027 \mathrm{MPa}$ & $1.028 \mathrm{MPa}$ & $300.55 \mathrm{~K}$ \\
Condenser outlet temperature & $300.3 \mathrm{~K}$ & $432.45 \mathrm{~K}$ & 0.0 \\
LPH outlet temperature & $433.07 \mathrm{~K}$ & $454.25 \mathrm{~K}$ & $0.14 \%$ \\
Deaerator outlet temperature & $453.33 \mathrm{~K}$ & $498.85 \mathrm{~K}$ & $0.20 \%$ \\
HPH outlet temperature & $495.46 \mathrm{~K}$ & $2249.62 \mathrm{~K}$ & $0.68 \%$ \\
Turbine inlet mass flow & $2249.62 \mathrm{~K}$ & $663.7 \mathrm{~kg} / \mathrm{s} \mathrm{per} \mathrm{pump}$ \\
Condensate pump mass flow & $663.7 \mathrm{~kg} / \mathrm{s} \mathrm{per} \mathrm{pump}$ & $749.54 \mathrm{~kg} / \mathrm{s} \mathrm{per} \mathrm{pump}$ & 0.0 \\
Feedwater pump mass flow & $747.1 \mathrm{~kg} / \mathrm{s} \mathrm{per} \mathrm{pump}$ & $1480 \mathrm{rpm}$ & 0.0 \\
Condensate pump speed & $1480 \mathrm{rpm}$ & $1496 \mathrm{rpm}$ & $0.33 \%$ \\
Booster pump speed & $1496 \mathrm{rpm}$ & $5122 \mathrm{rpm}$ & 0.0 \\
Feedwater pump speed & $5122 \mathrm{rpm}$ & 0.0 & 0.0 \\
\hline
\end{tabular}

TABLE 2: Time sheet for power change in transient analysis.

\begin{tabular}{|c|c|c|c|c|c|c|c|c|c|c|c|c|c|c|}
\hline Time (s) & 0 & 300 & 400 & 700 & 800 & 1100 & 1200 & 1500 & 1600 & 1900 & 2000 & 2300 & 2400 & 2700 \\
\hline Power & $100 \%$ & $100 \%$ & $90 \%$ & $90 \%$ & $80 \%$ & $80 \%$ & $70 \%$ & $70 \%$ & $60 \%$ & $60 \%$ & $50 \%$ & $50 \%$ & $40 \%$ & $40 \%$ \\
\hline
\end{tabular}

using the material of stainless steel. Extraction steam from turbines in shell side of heater is modeled by time dependent junctions and time dependent volumes, the parameters of which are controlled the same as the turbine extraction using controller component in RELAP. Isolate valves are modeled in each subcircuit to provide the ability of simulating the disconnection operation situation (isolate valves are not presented in the nod map for concision). Shell sides of feedwater heaters contain two-phase flow and heat transfer, especially in high pressure feedwater heater. Various sources of HPH's inlet boundary in shell side, including extraction steam from turbine and water for MSR and next level heaters' drain water, contribute to rapid and dramatic change of twophase flow, leading to calculation divergence. To solve this problem, an equivalent method is used in HPH's heat transfer model. All inlet boundary conditions of HPH's shell sides are set to saturated water; that is, void fraction is zero, and an internal heat source with heat power equaling the enthalpy difference between the actual condition of shell sides' heat source and the saturated water boundary we set is added to the water sides. This method guarantees the heat transfer effect in $\mathrm{HPH}$.

Dissolved gases in feedwater may lead to severe corrosion damage in thermal-hydraulic system; thus, deaerator is used to avoid it in all power plants [11]. The spray-type deaerator adopted in this system consists of a horizontal cylindrical vessel, which serves as both the deaeration section and the feedwater storage tank. The pressure of deaerator is required to be maintained by extraction steam from turbine to ensure the feedwater pressure is enough to meet the need of net positive suction head at pump inlet. Main body of deaerator is modeled by a combination of a ten-volume pipe (730) and a branch (726). Time dependent volumes represent the preheating source from MSR, number $6 \mathrm{HPH}$, and HPT (700, 708 , and 716, resp.), which will mix up with condensed water in branch and then flow to pipe 730. Time dependent volumes 690 and 743 are set to keep pressure of deaerator, and time dependent junction 741 is set to govern the water level by proportional-integral controller. The dramatic change in void fraction of two-phase mixture flow at top of deaerator leads to preheating inadequacy at the exit. This is solved by using a heat structure with internal heat source adding to five former volumes of pipe 730 . The valves of thermal-hydraulic system in conventional island are all modeled according to their function and operation logic.

Boundary data for various operation conditions has been set in input data deck, more specifically the turbine load for $100 \%, 90 \%, 80 \%, 70 \%, 60 \%, 50 \%$, and $40 \%$. In addition to achievement of required steady state for $100 \%$ power condition, transient simulation of turbine load change from $100 \%$ full power to $40 \%$ low power step by step has also been modeled.

\section{Validation and Discussion}

Steady states for turbine load from $100 \%$ to $40 \%$ individually are performed by running $5000 \mathrm{~s}$ without perturbation. All calculation values are compared with nominal design values, and the errors between them are less than $2 \%$. Since key parameters' errors are not more than $1 \%$, the various power conditions are modeled correctly and values of $100 \%$ power steady state are tabulated in Table 1.

Transient analysis is achieved by performing change power by time as shown in Table 2, running $2700 \mathrm{~s}$ in total.

The validation of transient calculation has been carried out, and all the calculation values of steady state of turbine load for $90 \%, 80 \%, 70 \%, 60 \%, 50 \%$, and $40 \%$ are compared with the design values; the errors between them are less than $10 \%$, and the major parameters' errors are less than 5\%. Some of the typical parameters' values and trends of transient run are illustrated in Figures 4-6. Figure 4 shows transient change of mass flow for turbine inlet, booster pumps inlet, and single SG inlet, and the parameters' values decline stage by stage 


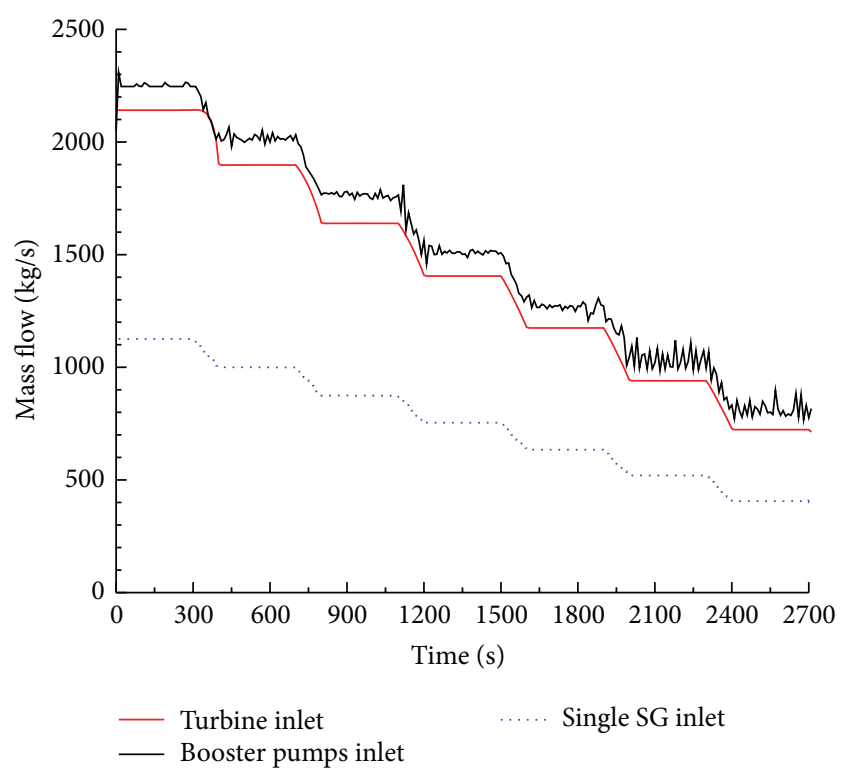

FIGURE 4: Transient change of mass flow for turbine inlet, booster pump inlet, and single SG inlet.

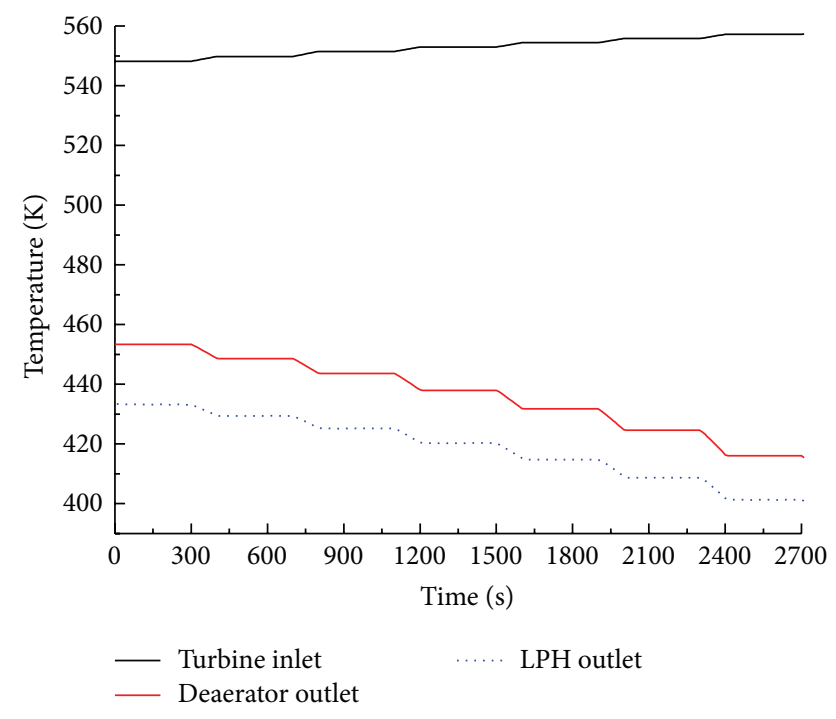

FIGURE 5: Transient change of temperature for turbine inlet, LPH outlet, and deaerator outlet.

as power decreases. Since the pump component is sensitive to the working point, the pressure surge caused by density difference and fluid accumulation in deaerator leads some small fluctuation for booster pumps inlet mass flow. Due to the tolerance of this model and main feedwater regulating valve, the fluctuation does not pass to the SG inlet mass flow. The mass flow at booster pump inlet is twice as much as it at single steam generator inlet, which is reasonable. The mass flow at turbine inlet is a little less than flow at booster pump inlet (equaling SG inlet total mass flow). The difference

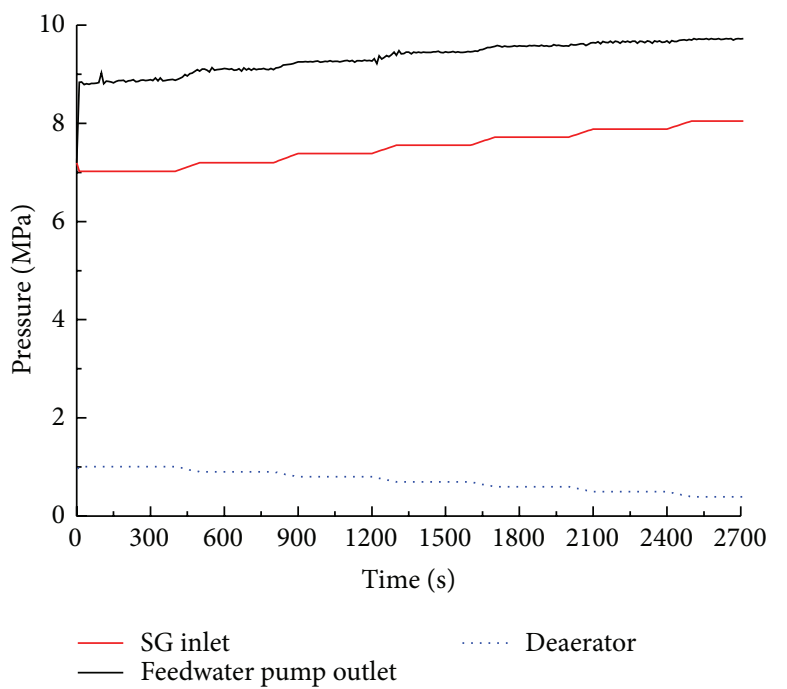

FIGURE 6: Transient change of pressure for SG inlet, deaerator, and feedwater pump outlet.

between them is exactly live steam extraction before steam from SG to HPT, which is delivered to MSR for reheating.

The heat transfer power between first and secondary side of SG is described by (1), where $K$ is heat transfer coefficient, which is seen as a constant, and $A$ is heat transfer area. $T_{\text {av }}$ is average temperature of coolant in primary loop, $T_{s}$ is the saturate temperature of secondary side of SG. The heat transfer power is proportional to difference between $T_{\mathrm{av}}$ and $T_{s}$. Concerning both thermodynamic cycle efficiency in second loop and reactivity adjustment requirement caused by the change of coolant volume, the design NPP adopted is that reactor inlet temperature maintained constant while coolant average temperature declines within a certain acceptable range as power reduces, and steam temperature increases as power reduces. Consider

$$
P=K A\left(T_{\mathrm{av}}-T_{s}\right)
$$

Figure 5 shows transient change of temperature for turbine inlet, low pressure feedwater heaters outlet, and deaerator outlet. The temperature in turbine inlet increases gradually as load reduces, which is consistent with the design of NPP. Since the turbine extraction to heaters decreases as the power decreases, the water temperature at each level heaters and deaerator exit also declines.

Figure 6 shows transient change of pressure for deaerator, feedwater pump outlet, and SG inlet. The deaerator pressure is controlled the same as the extraction steam, which declines as power drops. The head of pump is inversely proportional to the flow, so the pressure at the outlet of pumps increases as power decreases.

Since the errors of calculation results of steady state are in an acceptable range and turbine load reduction transient trend is reasonable, the model of conventional island is correct. 


\section{Conclusions}

A full scope modeling for secondary circuit in conventional island of Chinese large-scale advanced PWR has been developed based on RELAP5. Steady state for turbine load from $100 \%$ to $40 \%$ individually is achieved by this model, and the validation of the parameters shows that all the errors between the calculation values of steady state and transient and practical design values are less than $10 \%$, and the major parameters' errors are less than $2 \%$, which is acceptable.

This model is developed according to actual plant layout without simplification in the amount of equipment, which is convenient for simulating disconnection operation situation of some equipment. The equivalent internal heat source method is used both in HPFHs' noncontact heat exchange model and deaerator's mixing heat transfer model to solve the calculation divergence problem caused by dramatic twophase condition change while guaranteeing the heat transfer efficiency. The transient model of turbine load from $100 \%$ to $40 \%$ provides an easy way to observe the parameters' change in different conditions. Further study will be focused on optimization of the model, peak load simulation, and accident scenario based on this model.

\section{Conflict of Interests}

The authors declare that there is no conflict of interests regarding the publication of this paper.

\section{References}

[1] L. L. Briggs, "A new balance-of-plant model for the SASSYS1 LMR systems analysis code," Transactions of the American Nuclear Society, vol. 60, p. 709, 1989.

[2] H. P. Planchon, R. M. Singer, D. Mohr, E. E. Feldman, L. K. Chang, and P. R. Betten, "The experimental breeder reactor II inherent shutdown and heat removal tests-results and analysis," Nuclear Engineering and Design, vol. 91, no. 3, pp. 287-296, 1986.

[3] H. A. Larson, E. M. Dean, J. F. Koenig, J. G. Gale, and W. K. Lehto, "Dynamic simulator for nuclear power plants (DSNP): development, verification and expansion of modules," in Proceedings of the International Conference on Power Plant Simulation, CONF-851007-15, Cuernavaca, Mexico, November 1984.

[4] P. Sharma, K. Natesan, P. Selvaraj, V. Balasubramaniyan, and P. Chellapandi, "Dynamic modeling of steam water system of prototype fast breeder reactor using RELAP code," Annals of Nuclear Energy, vol. 68, pp. 209-219, 2014.

[5] C.-Y. Yang, T. K. S. Liang, B. S. Pei, C. K. Shih, S. C. Chiang, and L. C. Wang, "Development and application of a dual RELAP5-3D-based engineering simulator for ABWR," Nuclear Engineering and Design, vol. 239, no. 10, pp. 1847-1856, 2009.

[6] Q. Zhang, R. Guo, C. Zhang, X. Chen, and B. Wang, "Radioactive airborne effluents and the environmental impact assessment of CAP1400 nuclear power plant under normal operation," Nuclear Engineering and Design, vol. 280, pp. 579-585, 2014.

[7] Nuclear Safety Analysis Division, RELAPS/MOD3.3 Code Manual Volume I: Code Structure, System models, and Solution Methods, Information Systems Laboratories, 2001.
[8] M. Dulau and D. Bica, "Mathematical modelling and simulation of the behaviour of the steam turbine," Procedia Technology, vol. 12, pp. 723-729, 2014.

[9] T. C. Elliott, K. Chen, and R. Swanekamp, Standard Handbook of Powerplant Engineering, McGraw-Hill, New York, NY, USA, 2nd edition, 1997.

[10] M. Álvarez-Fernández, L. D. Portillo-Valdés, and C. AlonsoTristán, "Thermal analysis of closed feedwater heaters in nuclear power plants," Applied Thermal Engineering, vol. 68, no. 1-2, pp. 45-58, 2014.

[11] S. C. Stultz, Steam: Its Generation and Use, Babcock \& Wilcox, 41st edition, 2005. 


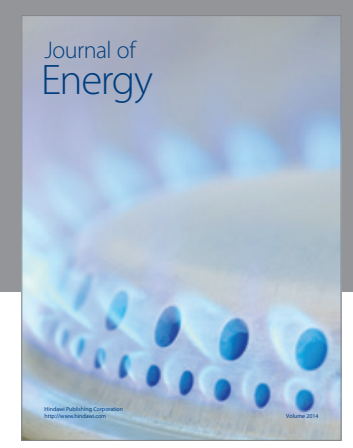

Journal of

Industrial Engineering
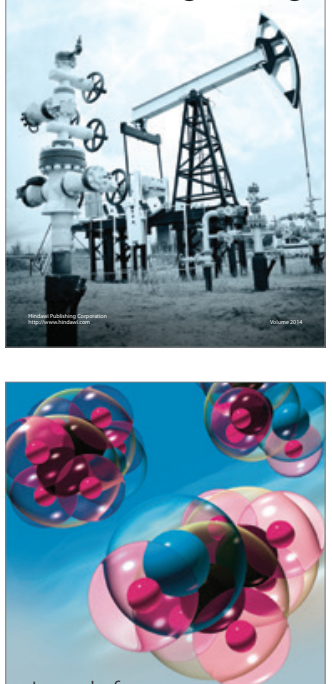

Fuels
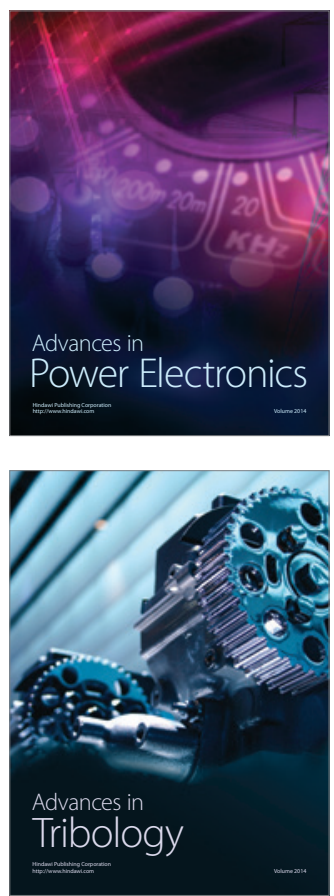

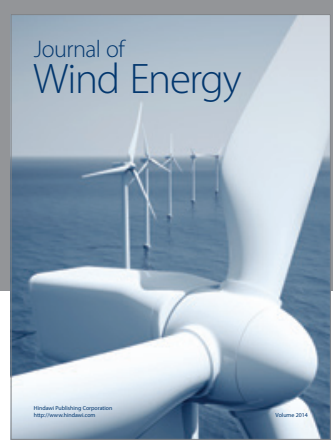

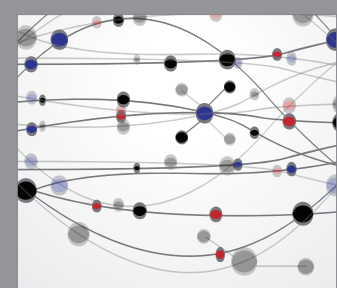

The Scientific World Journal

Submit your manuscripts at http://www.hindawi.com

Journal of

Structures
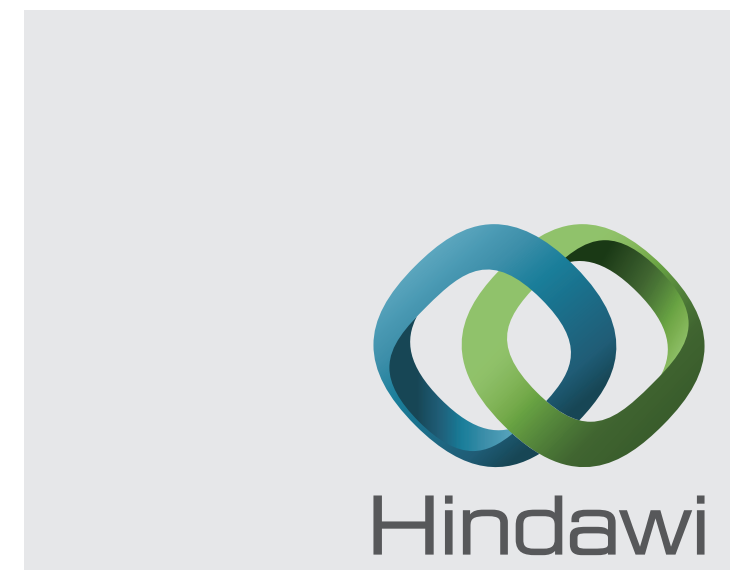

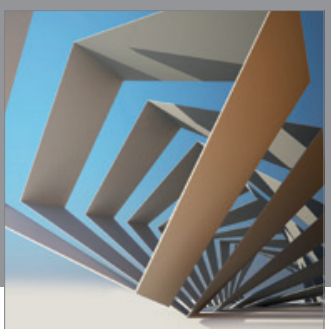

Rotating

Machinery
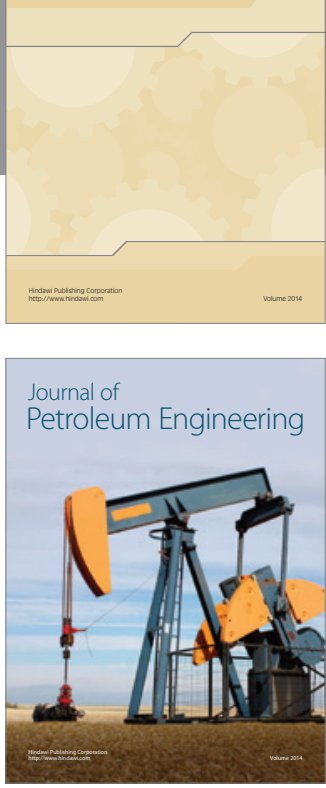

Journal of

Solar Energy
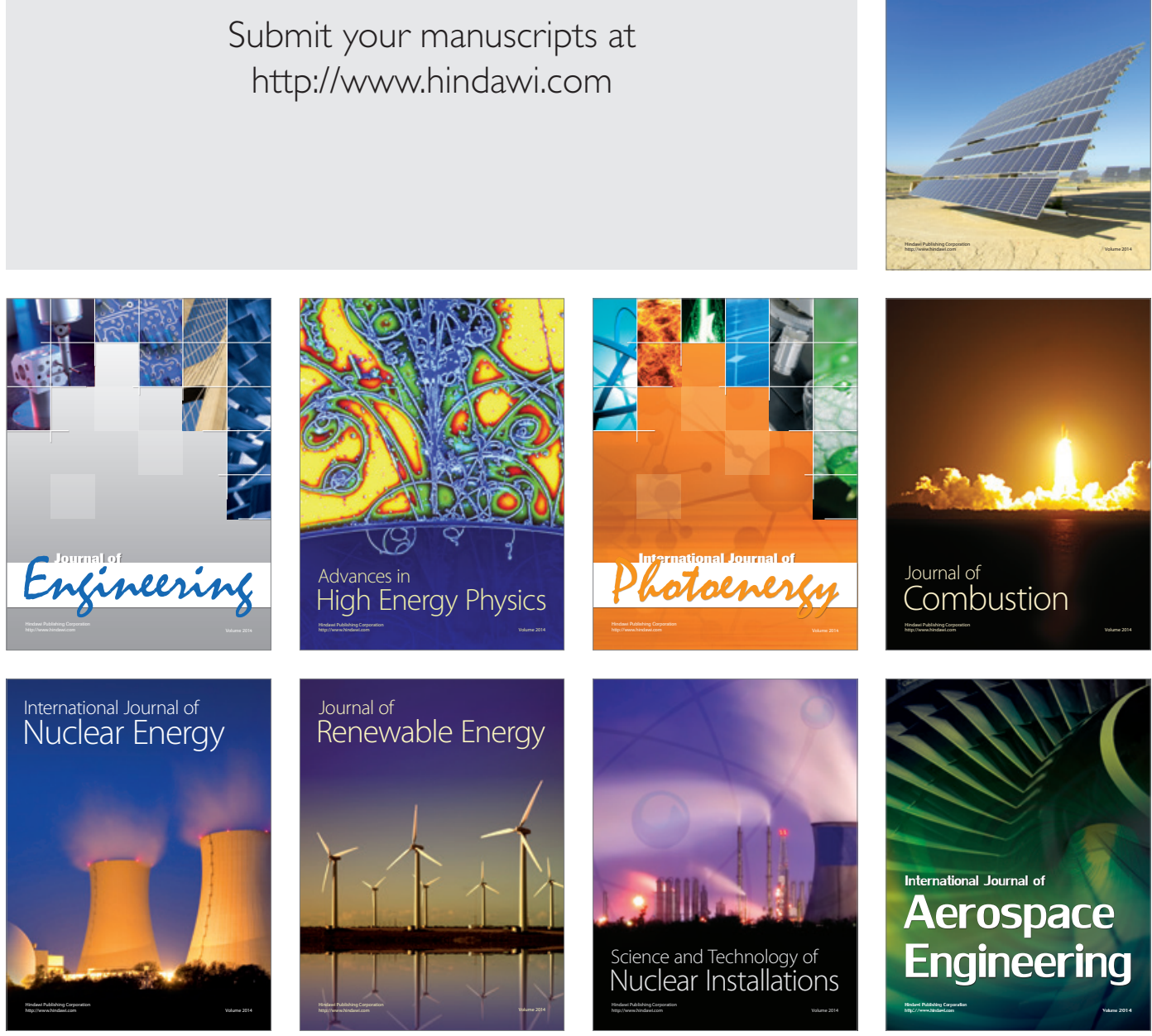